\title{
Presynaptic Differentiation Induced in Cultured Neurons by Local Application of Basic Fibroblast Growth Factor
}

\author{
Zhengshan Dai and H. Benjamin Peng \\ Department of Cell Biology and Anatomy and Curriculum in Neurobiology, University of North Carolina at Chapel \\ Hill, Chapel Hill, North Carolina 27599
}

\begin{abstract}
Recent studies have suggested a role for molecules residing at the muscle surface in signaling presynaptic development at the neuromuscular junction (NMJ). Since heparan sulfate-proteoglycan is a major component of the extracellular matrix of skeletal muscle, factors that are bound to this proteoglycan, such as basic fibroblast growth factor (bFGF), are in a strategic position for neuronal signaling. To test this idea, we applied bFGF to cultured Xenopus spinal cord neurons and monitored the change in intracellular $\mathrm{Ca}^{2+}$ level with fura-2 ratio imaging. In one-third of the neurons, local application of bFGF elicited a 30-140\% increase in intracellular $\mathrm{Ca}^{2+}$ level. $\mathrm{Ca}^{2+}$-free medium or suramin abolished this change. Latex beads coated with bFGF induced clustering of synaptic vesicles at the bead-neurite contacts as evidenced by anti-synaptotagmin antibody labeling and electron microscopy. This response was also blocked by $\mathrm{Ca}^{2+}$-free medium and by suramin. Uncoated beads or beads coated with PDGF were ineffective. This induction was also inhibited by a tyrosine kinase inhibitor, tyrphostin RG-50864, suggesting the role of receptor tyrosine kinase activation in this process. In addition, bFGFcoated beads also induced the localization of depolarization-dependent $\mathrm{Ca}^{2+}$ influx to the bead-neurite contacts. In contrast, depolarization caused a distributed $\mathrm{Ca}^{2+}$ elevation in untreated neurites. These results suggest that local presentation of bFGF can mimic the muscle target in signaling the development of both a cytoplasmic and a membranous specialization for excitation-secretion coupling observed at the NMJ.
\end{abstract}

[Key words: neuromuscular junction, basic fibroblast growth factor (bFGF), calcium, synaptic vesicles, Xenopus]

During the formation of the neuromuscular junction (NMJ), the contact between nerve and muscle induces the development of synaptic specializations. This is manifested by the clustering of ACh receptors (AChRs) on the postsynaptic side and the clustering of synaptic vesicles (SVs) and voltage-gated calcium channels on the presynaptic side (Hall and Sanes, 1993). Thus,

\footnotetext{
Received Jan. 17, 1995; revised Mar. 20, 1995; accepted Mar. 23, 1995.

We thank Dr. Richard Burry for the gift of synaptotagmin antibody, Synergen for the gift of bFGF and Rhone-Poulenc Rorer for the gift of tyrphostin. We are grateful to Ms. Victoria J. Madden (Department of Pathology, UNC) for her help with ultramicrotomy and to Dr. Ellen Weiss for reading the manuscript. This research was supported by NIH Grant NS23583 and the Muscular Dystrophy Association.

Correspondence should be addressed to Dr. H. B. Peng, Department of Cell Biology and Anatomy, University of North Carolina, CB \#7090, 108 Taylor Hall, Chapel Hill, NC 27599-7090.

Copyright (C) 1995 Society for Neuroscience $0270-6474 / 95 / 155466-10 \$ 05.00 / 0$
}

the nerve-muscle interaction leads to the establishment of a spatial coupling between the transmitter release and detection mechanisms, which is essential for the neurotransmission at this fast synapse. Extensive studies have provided a detailed understanding of the process of postsynaptic development (reviewed in Hall and Sanes, 1993). In contrast, our understanding of the cellular and molecular mechanisms of presynaptic development is rather limited.

Previous studies have suggested that the inductive signal for presynaptic differentiation originates, at least in part, from the target (Dan and Poo, 1994). When a muscle cell is manipulated into contact with a spinal cord neurite, a rapid onset of transmitter release can be elicited (Xie and Poo, 1986). However, inappropriate contact, such as that formed between two motoneurons or between a neuron and a glass bead, does not elicit such response. We have recently shown that this manipulated ncrve-musclc contact also induces an elevation in the presynaptic $\mathrm{Ca}^{2+}$ level and this increase is causal to the onset of the transmitter release (Dai and Peng, 1993). Neuron-neuron contact, on the other hand, does not elicit this $\mathrm{Ca}^{2+}$ signal, thus suggesting the specificity of muscle-derived signals in triggering presynaptic development. In addition to manipulated nervemuscle contacts, an elevation in presynaptic $\mathrm{Ca}^{2+}$ has also been observed at spontaneous nerve-muscle contacts (Dai and Peng, 1993; Zoran et al., 1993).

The immediate onset of transmitter release and presynaptic $\mathrm{Ca}^{2+}$ rise induced by target contact suggests that presynaptic development is triggered by molecules residing on the surface of the muscle cell. This is supported by the observation that muscle membrane extract can also cause a significant increase in neuritic $\mathrm{Ca}^{2+}$ in cultured Helisoma neurons (Zoran et al., 1993). Furthermore, regenerating motoneurons can form presynaptic specializations on synaptic basal lamina in the absence of muscle (Sanes et al., 1978). These studies indicate that the cue for presynaptic development probably resides within the extracellular matrix (ECM) of the skeletal muscle. Heparan-sulfate proteoglycan (HSPG) is a prominent ECM molecule of skeletal muscle (Anderson and Fambrough, 1983; Anderson et al., 1984; Swenarchuk et al., 1990). Recent studies have shown that one of the major functions of HSPG is to serve as a storage site for heparin-binding growth factors (HBGFs) (Ruoslahti, 1989; Klagsbrun and Baird, 1991; Ruoslahti and Yamaguchi, 1991). The role of these peptide growth factors in synaptogenesis is suggested by our recent results that local application of basic fibroblast growth factor (bFGF), a HBGF that is synthesized by a variety of mesoderm-derived cell types, induces the formation of acetylcholine receptor (AChR) clustering in cultured muscle 
cells (Peng et al., 1991a). Since these HSPG-bound factors can conceivably be presented to the motoneuron growth cone as it makes initial contact with the muscle cell, they seem to be ideal candidates for target-derived molecules that can effect presynaptic development.

In this study, we tested this hypothesis by presenting bFGFcoated beads to cultured Xenopus spinal cord neurons and examining the changes at bead-neurite contacts with regard to presynaptic differentiation. We report here that these beads induce the clustering of SVs and an accumulation of a $\mathrm{Ca}^{2+}$ influx machinery at their contacts with neurites.

\section{Materials and Methods}

Materials. Recombinant human bFGF was a kind gift of Synergen (Boulder, CO). PDGF was from Upstate Biotechnology, Inc. (Lake Placid, NY). Fura-2/AM was from Molecular Probes (Eugene, OR). Monoclonal antibody to synaptotagmin was a kind gift of Dr. Richard Burry (Ohio State University, Columbus, OH). FITC-conjugated goat-antimouse antibody was from Organo Technika (Treyburn, NC). Suramin was from FBA Pharmaceuticals (New York, NY). Tyrphostin RG50864 was a kind gift of Rhone-Poulenc Rorer (Horsham, PA). Polystyrene latex beads were from Polysciences (Warrington, PA).

Cell culture. Neurons were isolated from the neural tubes of stage 20-21 Xenopus embryos according to published methods (Peng et al. 1991b). They were plated on clean cover glass and cultured in Steinberg medium (60 mM NaCl, $0.7 \mathrm{mM} \mathrm{KCl,} 0.4 \mathrm{~mm} \mathrm{Ca}\left(\mathrm{NO}_{3}\right)_{2}, 0.8 \mathrm{~mm} \mathrm{MgSO}_{4}$, $10 \mathrm{~mm}$ HEPES, pH7.4, supplemented with $10 \%$ L-15 medium, $1 \%$ fetal bovine serum and $0.1 \mathrm{mg} / \mathrm{ml}$ gentamicin). The cultures were first maintained at $22^{\circ} \mathrm{C}$ overnight and then transferred into a $15^{\circ} \mathrm{C}$ incubator. They were used within $3 \mathrm{~d}$ after plating.

Induction of presynaptic specializations by beads. Polystyrene $10 \mu \mathrm{m}$ beads were washed with $95 \%$ ethanol for $30 \mathrm{~min}$ and then rinsed with phosphate buffered saline (PBS) by centrifugation with a microfuge and resuspension. They were then incubated with a solution containing 100 $\mu \mathrm{g} / \mathrm{ml}$ recombinant human bFGF for $2 \mathrm{hr}$, followed by two rinses. Labeling these coated beads with an antibody against bFGF followed by a fluorescent secondary antibody showed clearly the presence of bFGF on the bead surface. Beads were then applied to cultured neurons which already exhibited neuritic outgrowth. Control uncoated beads were also used in this study. For these beads, care was taken to prevent contaminating their surface with proteinaceous substance after the ethanol wash. Uncoated beads also adhered tightly to cultured neurons. In addition, beads coated with PDGF were also used as controls. These beads were coated with PDGF at concentrations similar to bFGF.

Immunocytochemistry. Cultures on cover glass were fixed with $4 \%$ paraformaldehyde in PBS, permeabilized by $0.25 \%$ saponin and blocked with PBS containing $1.5 \%$ bovine serum albumin. They were labeled with the antibody against synaptotagmin for $1 \mathrm{hr}$, washed, and then labeled with FITC-conjugated goat anti-mouse secondary antibody for $30 \mathrm{~min}$. They were mounted in a polyvinyl alcohol-based mounting medium containing $n$-propyl-gallate as an anti-bleaching agent.

Electron microscopy. Neural tubes were sliced into small pieces and plated into polylysine-coated $35 \mathrm{~mm}$ Lux Permanox plastic tissue culture dishes (Nunc, Naperville, IL). Within 2 d, neurites could be detected to emanate from these explants. bFGF-coated beads were then applied. Three days after bead addition, the cultures were fixed with

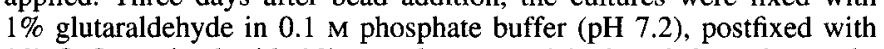
$1 \% \mathrm{OsO}_{4}$, stained with $1 \%$ uranyl acetate, dehydrated through an ethanol series and embedded in epoxy resin. After removal of the sample block from the culture dish, bead-bearing explants were selected by scoring the desired area of the block with a diamond marker, sawed off the block and thin-sectioned with a diamond knife. The sections were poststained with uranyl acetate and lead citrate and examined with a JEOL 200CX transmission electron microscope.

Calcium measurements. Neurons were incubated in medium containing $10 \mu \mathrm{M}$ fura-2/AM for $30 \mathrm{~min}$ at room temperature. Just prior to optical measurement, the culture medium was replaced with Ringer's solution $\left(120 \mathrm{mM} \mathrm{NaCl}, 2.5 \mathrm{~mm} \mathrm{KCl}, 10 \mathrm{~mm} \mathrm{CaCl}_{2}, 10 \mathrm{~mm}\right.$ HEPES, $\mathrm{pH}$ 7.4). Fluorescence images were obtained on a Zeiss IM-35 inverted microscope equipped with a Cohu SIT video camera and a Metaltek filter wheel with an electronic shutter. Images were acquired and processed with Image-1 software (Universal Imaging, West Chester, PA). Fura-2 loaded cells were examined through a Nikon $40 \times$ fluor objective
(N.A. 1.3) at excitation wavelengths of 340 and $380 \mathrm{~nm}$. Images were frame-averaged 16 times, background-subtracted, and stored on optical disk. The fluorescence ratios of the area of interest were calculated on line according to a stored calibration scheme predetermined with $\mathrm{Ca}^{2+}$ standards.

To stimulate the neuron, suprathreshold stimuli were delivered to the cell body of neurons via a pipette with a $5 \mu \mathrm{m}$ heat-polished tip. The stimuli consisted of square voltage pulses, $0.5 \mathrm{msec}$ in duration and 2 $6 \mathrm{~V}$ in amplitude, generated by a Digitimer isolated stimulator (model D52).

\section{Results}

Induction of SV clustering by bFGF-coated beads

To visualize the distribution of SVs, we labeled, fixed and permeabilized cultures with an antibody against synaptotagmin (Matthew et al., 1981; Burry et al., 1986; Peng et al., 1987) followed by a fluorescently conjugated secondary antibody. As shown in Figure $1, A$ and $B$, synaptotagmin was present along the length of the neurite which was not in contact with any target. Using bFGF-coated beads as experimental targets, we examined the redistribution of SVs in response to their stimulation. As shown in Figure $1, C$ and $D$ (arrowheads), SVs became more concentrated at bead-neurite contact sites after $1 \mathrm{~d}$. This SV labeling was intensified after 2-3 d of bead contact (Fig. $1 E-H)$. From observations made on 45 neurons, we calculated that about $85 \%$ of $2-3$ d old contact sites were associated with intense synaptotagmin labeling (see Fig. 4).

To confirm that the localization of synaptotagmin indeed represented clustering of SVs at bead-neurite contacts, electron microscopy was conducted to visualize their ultrastructure. As shown in Figure 2, these micrographs revealed that beads established intimate contact with the neuritic membrane and 50-60 $\mathrm{nm}$ clear vesicles were clustered at these sites. Large dense-core vesicles $(90-100 \mathrm{~nm})$ were also observed in the vicinity of contacts but, unlike small clear vesicles, were not clustered (Fig. 2, DV). These features are strikingly similar to the presynaptic nerve terminal at the NMJ (Peng et al., 1987; Matteoli et al., 1988).

To test the specificity of bFGF-coated beads in inducing SV clustering, we also treated cultures with uncoated beads. As shown Figure 3, $A$ and $B$, no synaptotagmin concentration could be detected at these bead-neurite contacts. To study whether the difference in efficacy between these two kinds of beads was due to adhesive strength, we compared the attachment of beads to neurites under a displacement force. Within $5 \mathrm{~min}$ of the establishment of bead-neurite contacts, a stream of culture medium was applied to the contact site from a micropipette $(5 \mu \mathrm{m}$ tip diameter) driven by 3 psi pressure from a pressure ejector. As the pipette was moved slowly toward the bead-neurite contact, most of the beads associated with the neurite could be blown away without the displacement of the neurite. In a smaller number of cases, the beads adhered strongly in such a way that its displacement also resulted in detachment of the neurite from the substratum. The percentage of beads that could not be removed without detachment of the neurite was found to be almost the same for bFGF and uncoated beads ( $25 \%$ out of $63 \mathrm{bFGF}$ beads on seven neurites versus $31 \%$ of 58 uncoated beads on seven neurites). This shows that stickiness alone can not account for the SV clustering effect of bFGF beads.

bFGF is a highly basic molecule with pI 9.6. Previous studies have shown that artificial polybasic peptides such as polylysine can induce SV accumulation when they are applied by beads (Burry, 1980; Peng et al., 1987). To test whether this effect is due to its charge alone, we studied the effect of beads 

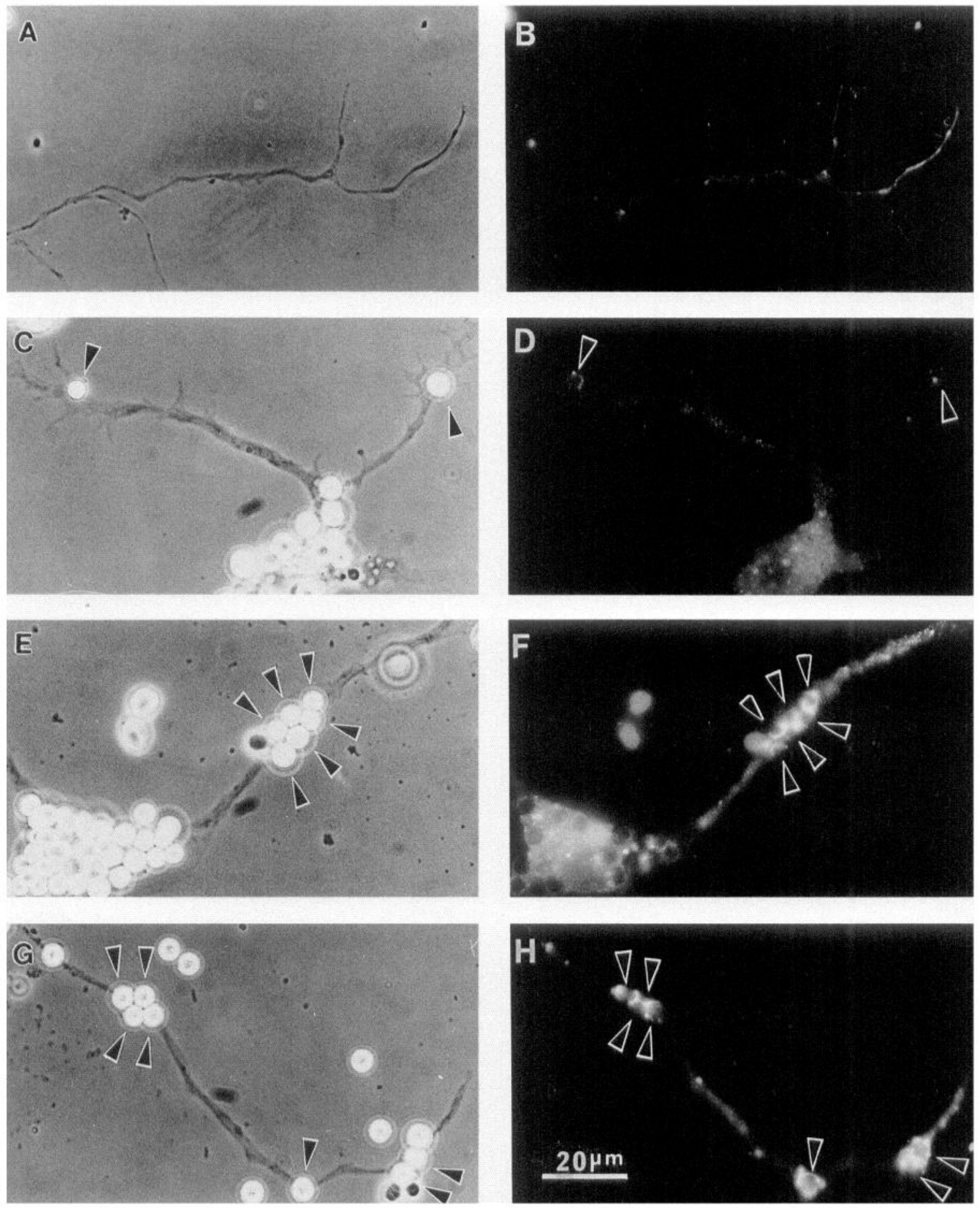

Figure 1. Localization of synaptotagmin within spinal-cord neurites at the contacts with bFGF-coated beads. Left column, phase-contrast images; right column, fluorescence images of synaptotagmin distribution. $A$ and $B$, Untreated neuron. Synaptotagmin was diffusely distributed along the neurite. $C$ and $D, 1 \mathrm{~d}$ bead-neurite contact. Localization of synaptotagmin at bead contacts (arrowheads) was detectable. $E$ and $F, 2 \mathrm{~d}$ bead-neurite contacts; $G$ and $H, 3 \mathrm{~d}$ bead-neurite contacts. Synaptotagmin became highly concentrated at these contacts. In contrast, the bead-free portion of the neurite was less prominent in synaptotagmin staining $(H)$.

coated with PDGF, a highly basic peptide growth factor with pI 9.8. As shown in Figure 3, $C$ and $D$, PDGF-coated beads were ineffective in inducing synaptotagmin localization. Thus, charge alone cannot explain the clustering effect of bFGF beads.

Quantitation of these results (Fig. 4) showed that SV clusters were specifically induced by local bead-mediated presentation of bFGF. To test whether this clustering effect was mediated by a ligand-receptor interaction, beads were applied to cultured neurons in the presence of suramin, a polyanion which interferes with the interaction of bFGF and other growth factors with their receptors (Betsholtz et al., 1986; Yayon and Klags- 

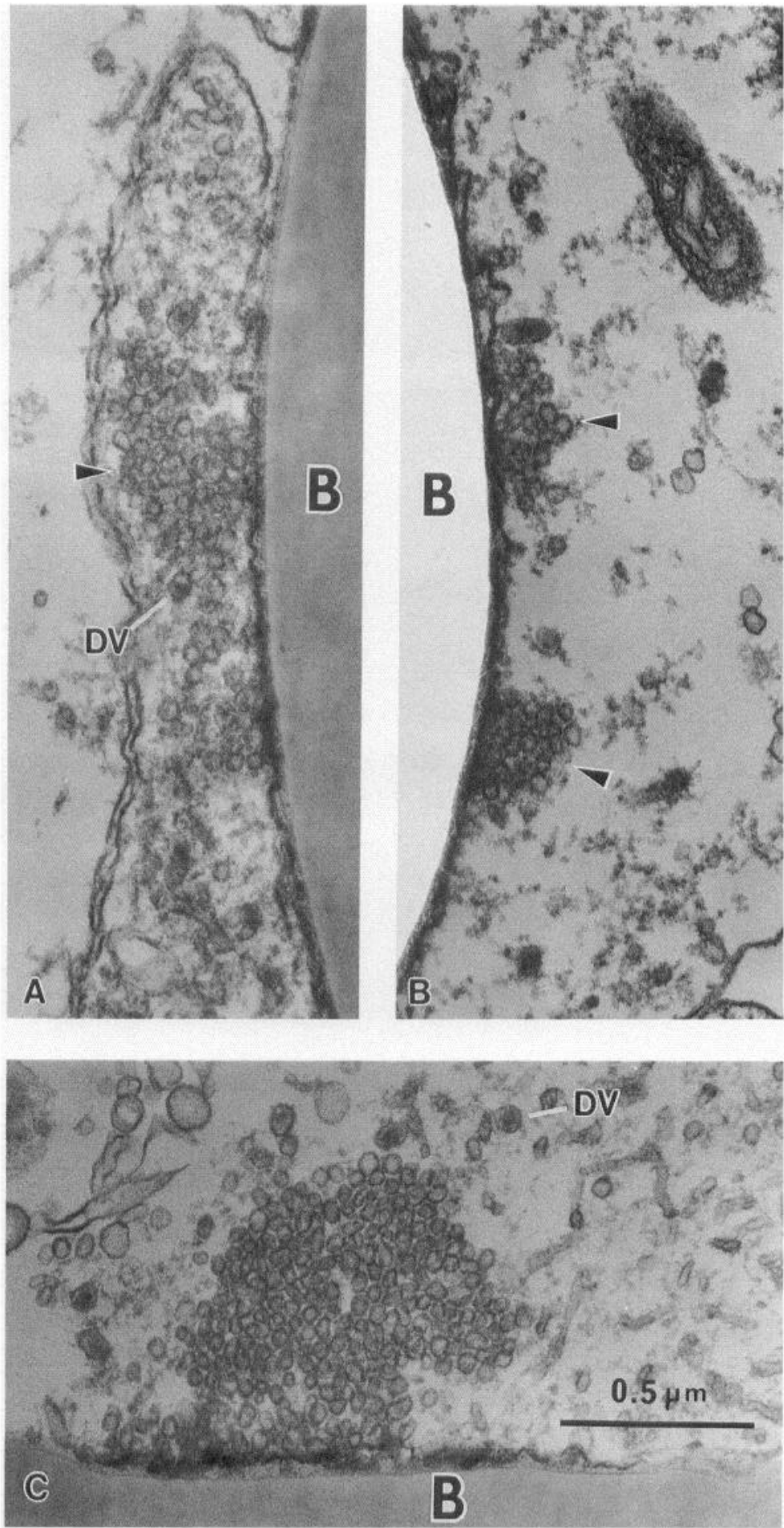

Figure 2. Clustering of SVs induced by bFGF-coated beads. These electron micrographs show the clustering of 50$60 \mathrm{~nm}$ clear vesicles (arrowheads) within the neurite at contact sites with beads $(B)$. Large dense-core vesicles $(D V)$ were not clustered. brun, 1990; Corfas et al., 1993). As shown in Figure 3, $E$ and $F$, and Figure 4 , suramin at $100 \mu \mathrm{M}$ completely inhibited the localization of synaptotagmin at neuritic contacts with bFGFcoated beads.

Western blot analyses of spinal cords isolated from Xenopus embryos at stage 20-24 (during which the neurons were isolated for culturing) with a monoclonal bFGF receptor antibody showed a band at $110 \mathrm{kDa}$ (data not shown). This shows that these neurons are competent in bFGF-mediated signaling. Since bFGF receptor is a tyrosine kinase (Lee et al., 1989; Johnson et al., 1990), we tested whether the bead-induced presynaptic development is dependent on the kinase activation. A tyrosine kinase inhibitor, tyrphostin RG-50864 which has been shown to interfere with several receptor tyrosine kinases (Lyall et al., 1989; Levitzki, 1992) was used in this study. We found that at a concentration of $80 \mu \mathrm{M}$, this inhibitor completely blocked the effect of bFGF bead-induced localization of synaptotagmin labeling (Fig. 3I,J). However, we could not detect a concentration of bFGF receptors at bead-neurite contacts by immunofluorescence. 

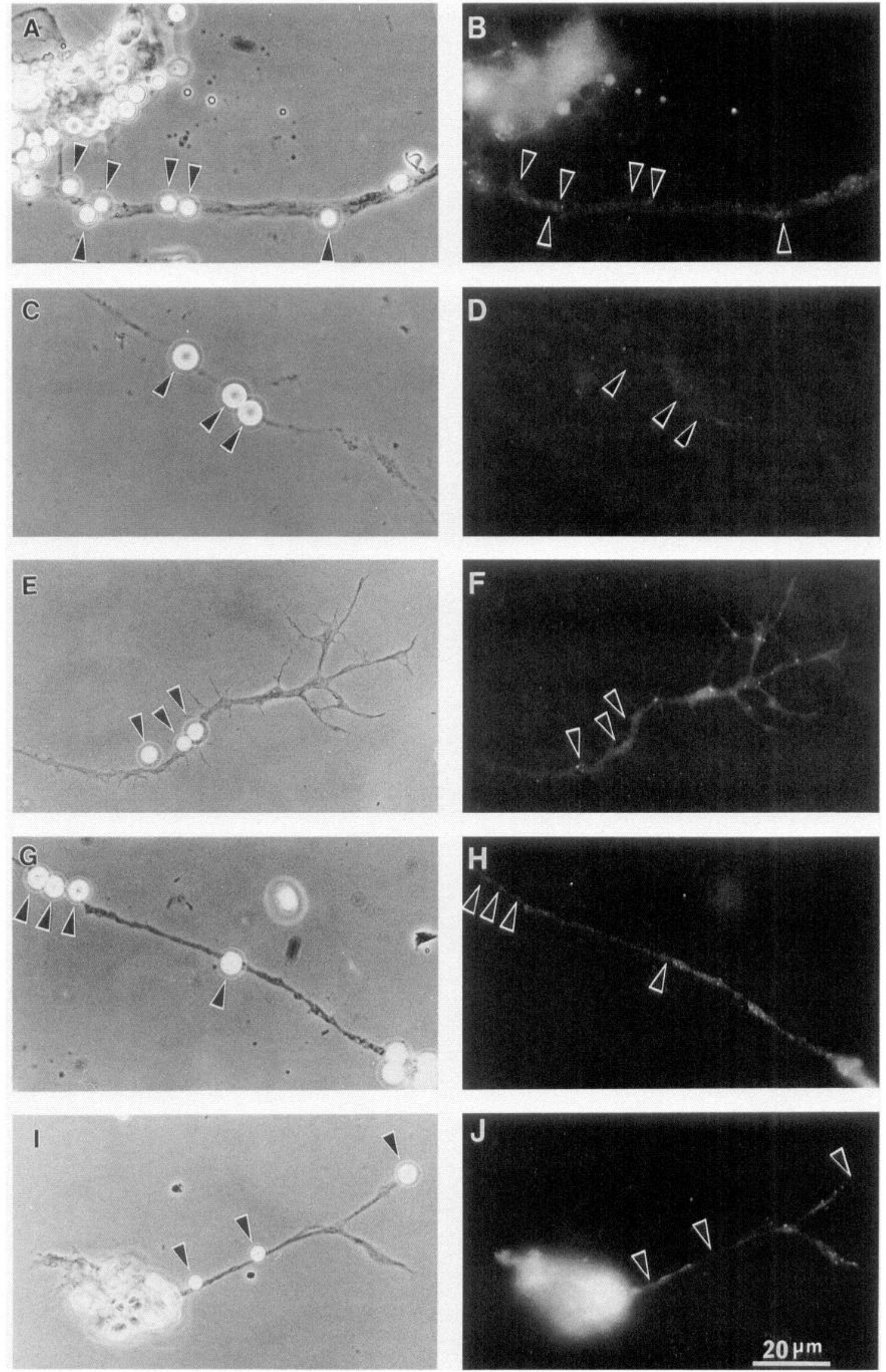


\section{The role of calcium in bead-induced presynaptic development}

To understand whether bFGF can mimic the muscle cell in eliciting an elevation in presynaptic $\mathrm{Ca}^{2+}$ level, we measured the neuronal $\mathrm{Ca}^{2+}$ concentration in response to bFGF application. Neurons were loaded with fura-2AM and bFGF was locally applied to the growth cone region with a micropipette containing $1 \mu \mathrm{g} / \mathrm{ml}$ ligand by a pressure ejector. As shown in Figure $5 A$, the growth cone responded to the bFGF puff by transiently elevating its $\mathrm{Ca}^{2+}$ level by $40 \mathrm{nM}$. In addition, the $\mathrm{Ca}^{2+}$ level in the soma also showed a smaller elevation due to the diffusion of bFGF from the pipette to that region (Fig. $5 B$ ). Significant $\mathrm{Ca}^{2+}$ response $(p<0.05)$, based on measurements before and after bFGF application, was observed in $30 \%$ of the spinal cord neurons tested (11 out of 34 ). In the responsive neurons, a mean $\mathrm{Ca}^{2+}$ elevation of $30 \mathrm{nM}$ was observed (see Fig. 8, first bar). These figures are similar to the response of neurons to manipulated muscle contact as previously described (Dai and Peng, 1993). In that study, it was found that $30 \%$ of the Xenopus neurons responded to muscle contact by an increase in intracellular $\mathrm{Ca}^{2+}$ level and transmitter release, probably reflecting the percentage of cholinergic neurons in this culture. When all neurons, including both responsive and nonresponsive ones, were scored together, a significant elevation in intracellular $\mathrm{Ca}^{2+}$ level over the resting level was still observed (see Fig. 8, second bar). In contrast, no neurons showed any response to puffs of Ringer's solution without bFGF to the growth cone (see Fig. 8). Thus, this elevation is not due to mechanical stimulation associated with ligand application. This $\mathrm{Ca}^{2+}$ transient was abolished in $\mathrm{Ca}^{21}$-free solution or in solution containing $200 \mu \mathrm{M}$ suramin (see Fig. 8), suggesting that the activation of bFGF receptor is responsible for this response.

To understand whether this $\mathrm{Ca}^{2+}$ signal is essential for the development of the presynaptic development, we conducted bead experiments in $\mathrm{Ca}^{2+}$-free solution. As shown in Figure 3, $G$ and $H$, and in Figure 4, the bead-induced synaptotagmin accumulation was abolished under this condition. This shows the $\mathrm{Ca}^{2+}$ dependency of the development of the presynaptic specialization.

\section{Calcium elevation induced by $b F G F$-coated beads}

In addition to the clustering of SVs, the contact of muscle target also induces presynaptic localization of depolarization-induced $\mathrm{Ca}^{2+}$ influx mechanism at the contact area (Funte and Haydon, 1993). To understand whether bFGF-coated beads can also mimic the muscle target in inducing this kind of membrane specialization, we examined the $\mathrm{Ca}^{2+}$ level of neurites before and after bead contacts. In bead-frec ncurons, the $\mathrm{Ca}^{2+}$ level was uniform throughout the soma and the neurite in the resting state (Fig. $6 A$ ). When the neuron was electrically stimulated at the soma, the $\mathrm{Ca}^{2+}$ level became elevated there as well as along the neurite (Fig. $6 B$ ). Results are quantified in Figure 9. Although the $\mathrm{Ca}^{2+}$ level was uniform in the resting state (Fig. 9A), the stimulusinduced elevation was more pronounced at sites closest to the soma, where $\mathrm{Ca}^{2+}$ rose to $250 \%$ of the resting level, than the distal region of the neurite, where a $65 \%$ increase was seen (Fig. $9 B, C$ ).

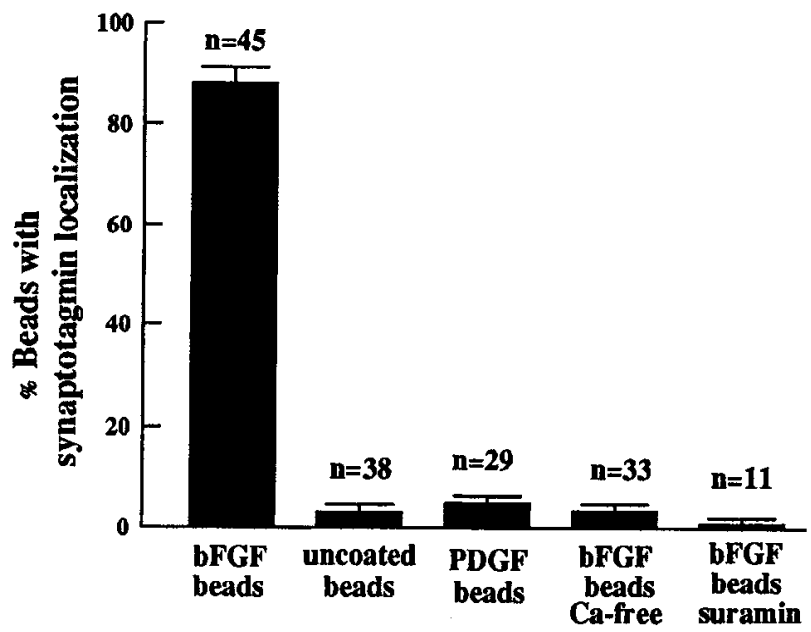

Figure 4. Quantitation of synaptotagmin localization at bead-neurite contacts. While bFGF-coated beads were effective in inducing this presynaptic specialization, uncoated beads or PDGF-coated beads were not. The efficacy of bFGF beads was abolished by $\mathrm{Ca}^{2+}$-frec solution or by suramin $(100 \mu \mathrm{M})$. The error bars denote SEs. Number of neurons scored in each case is noted above the bars.

In neurons that wcrc contactcd by bFGF-coated beads for 2 $3 \mathrm{~d}$, an elevation in resting neuritic $\mathrm{Ca}^{2+}$ level was detected at sites of contact in a fraction of the neurons. In neurons that responded to beads, the $\mathrm{Ca}^{2+}$ level at the beads reached a mean level that was $60 \%$ higher than the bead-free area (Fig. 10). When the soma of these neuron was electrically stimulated, a much higher elevation in $\mathrm{Ca}^{2+}$ was detected at bead-neurite contacts than the bead-free area (Fig. 7). As quantified in Figure 10, the bead contacts exhibited a mean elevation of $\mathrm{Ca}^{2+}$ about twice as high as the bead-free area of the neurites. This elevation was observed irrespective of the position of the beads along the neurite.

These data show that the depolarization-induced $\mathrm{Ca}^{2+}$ influx mechanism is uniformly distributed along the neurite in the absence of stimuli for presynaptic development. bFGF-coated beads induce a concentration of this mechanism to the site of bead-neurite contact, where the clustering of SVs also takes place as shown above.

\section{Discussion}

In this study, we have shown that bFGF-coated beads are effective stimuli for inducing presynaptic differentiation on cultured spinal cord neurons. They can mimic the muscle target to induce the formation of a cytoplasmic specialization as manifested by the clustering of SVs and a membrane specialization as manifested by the localization of a voltage-sensitive $\mathrm{Ca}^{2+}$ influx mechanism. These two types of specializations form the basis for the rapid, depolarization-dependent transmitter release at mature NMJs. Thus, the signal conveyed by these beads is comprehensive enough for the development of a full-range of specializations for presynaptic functions. Except for the stimulusinduced elevation in presynaptic $\mathrm{Ca}^{2+}$ level at the bead-neurite contacts, the data presented here did not address the releasability

$\leftarrow$

Figure 3. Lack of synaptotagmin localization under various experimental conditions. $A$ and $B$, Uncoated beads; $C$ and $D$, PDGF-coated beads; $E$ and $F$, bFGF-coated beads in the presence of $100 \mu \mathrm{M}$ suramin; $C$ and $H$, bFGF-coated beads in $\mathrm{Ca}^{2+}$-free medium; $I$ and $J$, bFGF-coated beads in the presence of $80 \mu \mathrm{M}$ tyrphostin RG-50864 (a tyrosine kinase inhibitor). Arrowheads point to bead-neurite contacts. 


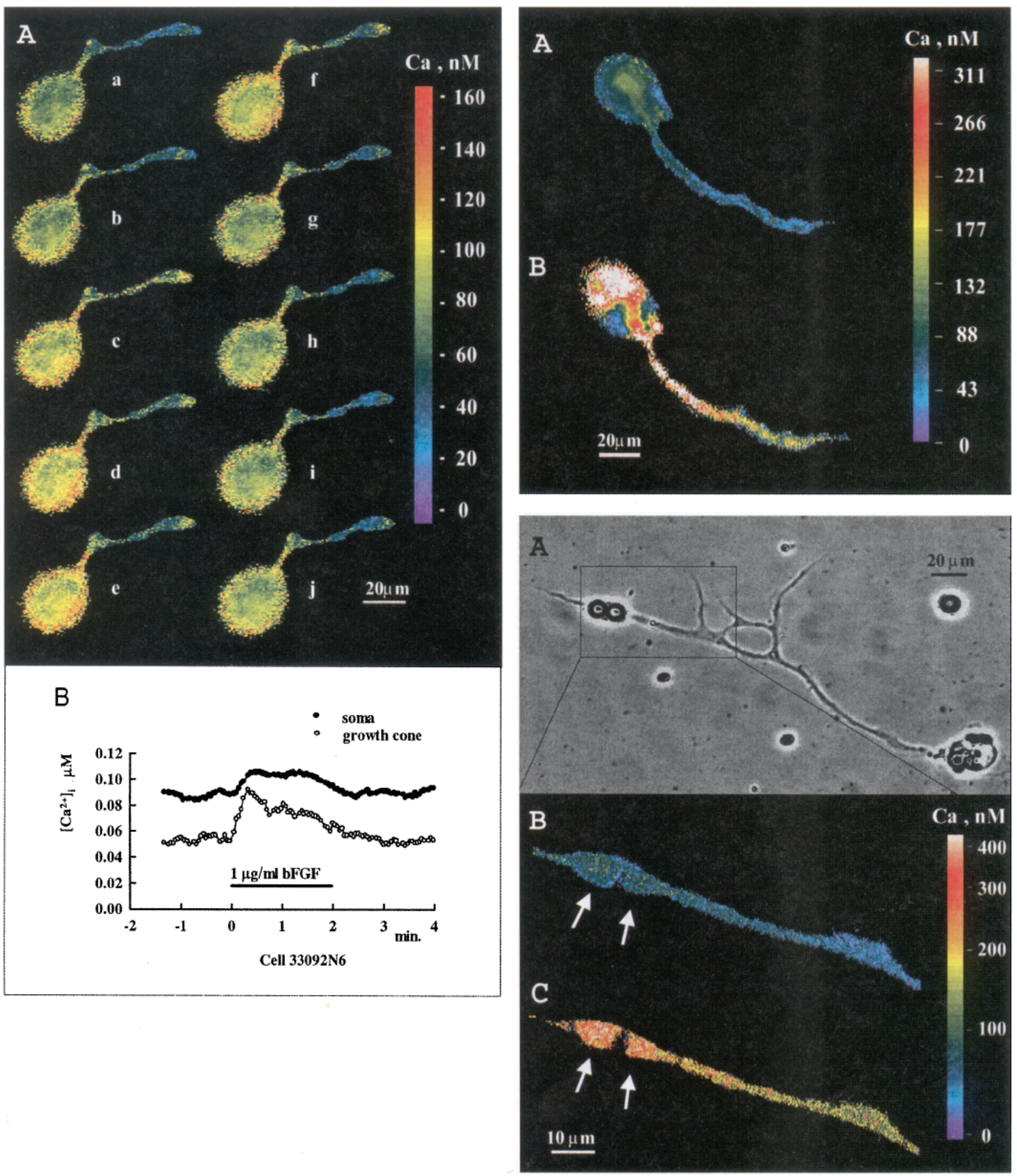

Figure 5 (left panels). Elevation of intracellular $\mathrm{Ca}^{2+}$ level induced by bFGF. bFGF was applied via a micropipette positioned about $10 \mu \mathrm{m}$ from the growth cone. The ligand was targeted to the growth cone, although diffusion also carried it to the soma area. $A$, Fura- 2 ratio images taken at intervals of $30 \mathrm{sec}(a-j)$. bFGF was ejected from the pipette immediately before image $c$ was taken and the application was stopped after image $f$ was taken. The pseudocolor scale shows $\mathrm{Ca}^{2+}$ concentration (nM). $B$, Quantitation of $\mathrm{Ca}^{2+}$ level in the growth cone and in the soma.

Figure 6. (right upper panel) $\mathrm{Ca}^{2+}$ elevation in a bead-free neuron. $A$, Resting state; $B$, after electrical stimulation of the soma. The stimulationinduced elevation in $\mathrm{Ca}^{2+}$ level was most pronounced in the proximal portion of the neurite.

Figure 7. (right lower panels) Elevation in neuritic $\mathrm{Ca}^{2+}$ at contacts with bFGF-coated beads. A bead-laden neuron is shown in phase contrast in $A$. The area containing the bead-neurite contacts is enlarged and shown in $B$ and $C$. In the resting state $(B)$, the $\mathrm{Ca}^{2+}$ level was slightly elevated 


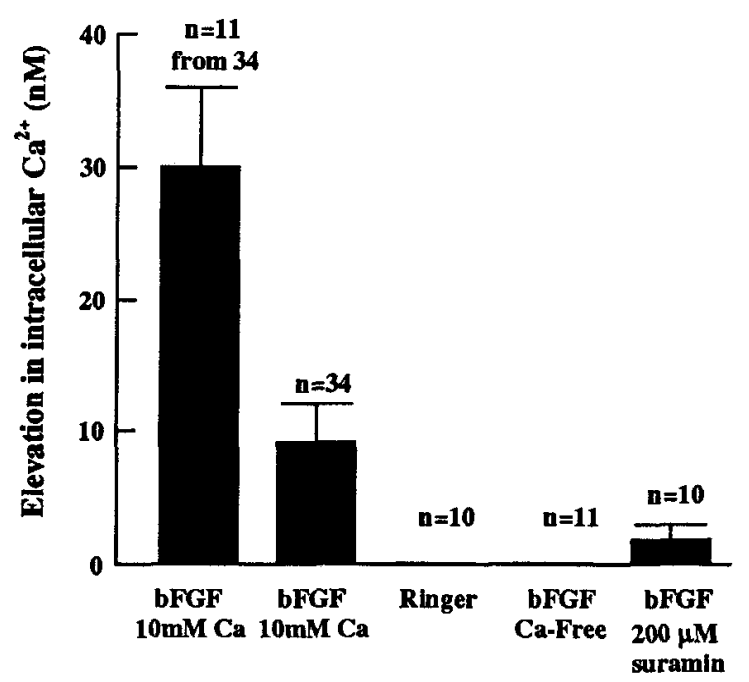

Figure 8. Quantitation of the elevation in growth cone $\mathrm{Ca}^{2+}$ level induced by bFGF The neurons were bathed in Ringer's solution containing $10 \mathrm{mM} \mathrm{Ca}^{2+}$ during the experiment. The first bar is the result of bFGF-responsive neurons only. The second bar summarizes results from all 34 neurons measured. $\Lambda$ pplication of Ringer's alone without bFGF did not induce $\mathrm{Ca}^{2+}$ elevation (third bar). The effect of bFGF was abolished if neurons were incubated in $\mathrm{Ca}^{2+}$-free Ringer's (fourth bar) or in Ringer's containing $200 \mu \mathrm{M}$ suramin (fifth bar). Error bars are SEs. Number of neurons tested is indicated above each bar. Significant differences $(p<0.01)$ exist between second and third, second and fourth, or second and fifth bars.

of the SVs clustered at those sites. However, our more recent studies with the fluorescent vesicular probe FM1-43 (Betz and Bewick, 1992) have shown that SVs clustered at contact sites with bFGF-coated beads can indeed undergo depolarization-dependent exocytosis and recycling (Dai and Peng, 1994). Thus, the presynaptic specialization formed on these artificial targets is indeed functional.

By assaying transmitter release or increase in intracellular $\mathrm{Ca}^{2+}$ accompanying manipulated or spontaneous nerve-muscle contact in vitro, previous studies have demonstrated a role for muscle in the establishment of the functional NMJ (Xie and Poo, 1986; Dai and Peng, 1993; Funte and Haydon, 1993; Zoran et al., 1993). Furthermore, it was found that molecules associated with the muscle membrane can induce these early presynaptic changes (Zoran et al., 1993). Since bFGF was previously shown to be bound to the surface of skeletal muscle cells (DiMario et al., 1989; Gonzalez et al., 1990), the current work thus further supports the role of target surface-bound molecules in the development of presynaptic specializations (Dan and Poo, 1994).

Since bFGF is a highly basic molecule, it is conceivable that its effect is mediated by the positive charge. Indeed, beads coated with polybasic compounds such as polylysine or polyornithine are inducers of SV clustering in cultured spinal cord and cerebellar neurons as previously shown (Burry, 1980; Peng et al., 1987). There is evidence that these polycations can actually mimic the endogenous ligands, such as bFGF, in activating their cell surface receptors (Dauchel et al., 1989; Kuo et al., 1990). However, not all basic molecules are effective in this induction.
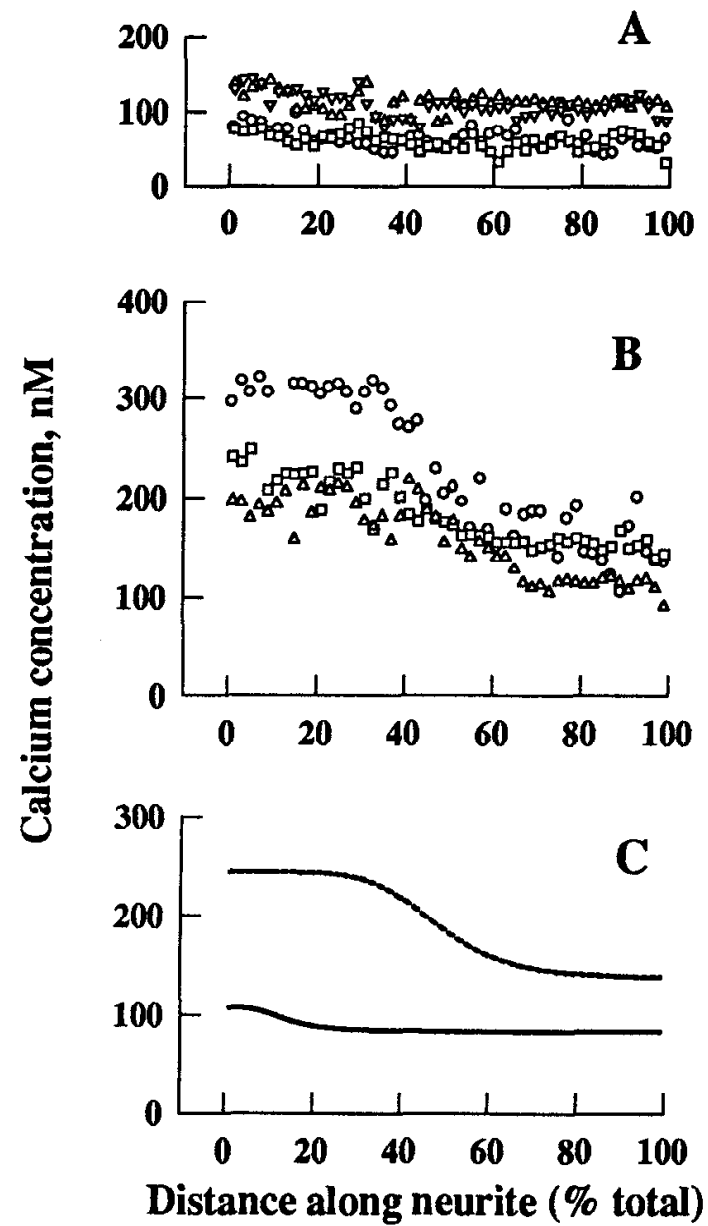

Figure 9. Quantitation of the $\mathrm{Ca}^{2+}$ distribution along the neurites without contact with beads. Each symbol represents a single neurite. For the measurement, each neurite was divided into 50 segments of equal length and the mean $\mathrm{Ca}^{2+}$ level of each segment was plotted. The neuritesoma junction was designated $0 \%$ distance, and the growth cone was designated $100 \%$ distance along the neurite. $A$, Before stimulation. Results from four neurites are plotted. $B$, After stimulation. Results from three neurites are plotted. $C$, Sigmoid least-square fit of all data points from three neurites (solid line, before stimulation; dotted line, after stimulation). The stimulus-elicited $\mathrm{Ca}^{2+}$ increase is most pronounced in the proximal part of the neurite.

As shown here, PDGF, another highly basic molecule, failed to induce SV clustering when applied on beads. Inhibition by suramin and by a tyrosine kinase inhibitor supports the notion that the SV clustering induced by bFGF beads is mediated by a receptor. It should be noted, however, that the effect of suramin is not specific to bFGF receptor. It has been shown that this drug also blocks ATP receptor (Edwards et al., 1992) which has been shown to be involved in the modulation of transmitter release at developing Xenopus NMJs (Fu and Poo, 1991).

The signal-transduction process for presynaptic development activated by bFGF-coated beads is $\mathrm{Ca}^{2+}$-dependent and may involve the activation of tyrosine kinases. Significantly, recent data have shown that the development of the postsynaptic specializa-

at sites of bead-neurite contact (arrows) in comparison to the bead-free portion of the neurite. After a single electrical stimulus delivered to the soma, the $\mathrm{Ca}^{2+}$ level was elevated in the neurite $(C)$. The increase at the bead-neurite contacts was much higher than the bead-free area. The image shown in $C$ was acquired within $1 \mathrm{sec}$ after somatic stimulation. 


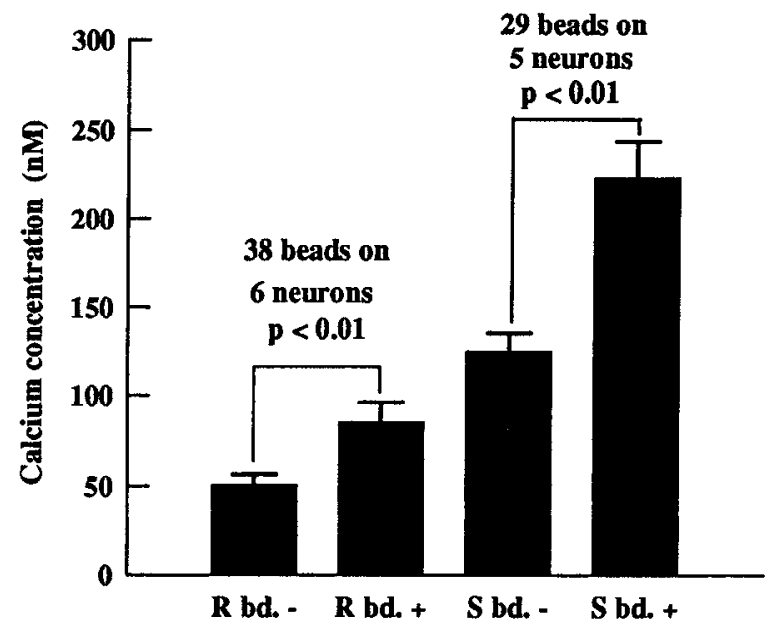

Figure 10. Comparison of $\mathrm{Ca}^{2+}$ concentration between bead-contact $(+)$ and bead-free $(-)$ area of the neurite. To measure the level under the bead, a $10 \mu \mathrm{m}$ circle was drawn around the bead and the mean $\mathrm{Ca}^{2+}$ concentration within this circle was calculated. In the resting state $(R)$, a small but significant elevation existed between the bead and bead-free areas. Stimulation $(S)$ greatly enhanced this difference.

tion on cultured muscle cells also involves activation of tyrosine kinases (Qu et al., 1990; Peng et al., 1991a; Wallace et al., 1991; Baker and Peng, 1993). The fact that beads can induce SV clustering and localization of $\mathrm{Ca}^{2+}$ influx wherever they come into contact with the neurite suggests that the chemosensitivity for presynaptic development is distributed over the entire neuritic membrane and beads can locally induce this development. The mechanism for the localization of SVs at bead-neurite contacts may involve local organization of a cytoskeletal specialization, since previous ultrastructural studies have shown the presence of an actin network within the nerve terminal at NMJs in vivo and in vitro (Peng, 1983; Hirokawa et al., 1989). This hypothesis is supported by our recent observation that F-actin, as visualized by rhodamine-phalloidin labeling, is concentrated at bead-neurite contacts (Z.D. and H.B.P., unpublished observations). Furthermore, in Aplysia growth cones, small polybasic beads induce the rapid assembly of actin networks at the membrane-bead interface (Forscher et al., 1992). These actin-containing structures, termed inductopodia, can propel beads to move on the surface of the growth cone. A local actin network within the neurite may interact with proteins on SVs, such as synapsins, to effect their localization (Hirokawa et al., 1989; Betz and Henkel, 1994). A previous study showed that the expression of synapsin IIb in neuroblastoma cells can promote synaptogenesis (Han et al., 1991). Thus, the contact with the postsynaptic target may first activate a tyrosine-kinase based signal-transduction mechanism, leading to the local assembly of an actin-based cytoskeletal specialization. This specialization then interacts with SVs via their intrinsic proteins to effect their clustering.

The localization of the depolarization-dependent $\mathrm{Ca}^{2+}$ influx mechanism at head-neurite contacts is likely due to the accumulation of $\mathrm{Ca}^{2+}$ channels which are known to be clustered at presynaptic active zones at the NMJ (Robitaille et al., 1990; Cohen et al., 1991). We have attempted to visualize the localization of $\mathrm{Ca}^{2+}$ channels at bead-neurite contacts with fluorescent $\omega$-conotoxin GVIA, a specific probe for $\mathrm{N}$-type $\mathrm{Ca}^{2}{ }^{2}$ channels. However, no significant concentration of the toxin binding sites at bead-neurite contacts has been observed. This could mean that the density of $\mathrm{Ca}^{2+}$ channels is not high enough to be visualized with this fluorescent method. Alternatively, this toxin may not be a good marker for the $\mathrm{Ca}^{2+}$ channel in Xenopus embryonic neurons, since our electrophysiological studies have shown that a large portion of the $\mathrm{Ca}^{2+}$ current blocked by this toxin is reversible (Z.D., unpublished observation). Further studies are necessary to understand the physiological basis of this membrane specialization induced by beads.

In addition to the possible effect on $\mathrm{Ca}^{2+}$ channel clustering when locally applied via beads, bFGF also directly stimulates a transient elevation in neuronal $\mathrm{Ca}^{2+}$ level by itself when applied in the bath. The mechanism of this stimulation is not known, although a previous study has documented that bFGF can upregulate voltage-dependent $\mathrm{Ca}^{2+}$ channels in retinal glia cells (Puro and Mano, 1991). bFGF beads, on the other hand, elicits a prolonged elevation in $\mathrm{Ca}^{2+}$ level at the bead-neurite contacts in the resting state (Fig. 10). This prolongation may be due to the increased density of $\mathrm{Ca}^{2+}$ channels clustered at the beads.

Previously, we showed that bFGF-coated beads are also effective in inducing the formation of AChR clusters on cultured muscle cells (Peng et al., 1991a). This raises the possibility that a target-derived molecule can be used as both pre- and postsynaptic inducers. In addition to bFGF, the HSPG on the surface of muscle cells can also harbor other muscle-derived peptide growth factors, including additional members of the FGF family such as FGF-5 and FGF-6 (DeLapeyrière et al., 1993; Han and Martin, 1993; Hughes et al., 1993), and the newly discovered heparin-binding growth-associated molecule (HB-GAM) (Merenmies and Rauvala, 1990; Li et al., 1990). All of these factors are potential candidates for signaling presynaptic development. In addition, HSPG can also interact with other components of the ECM on skeletal muscle, such as agrin (Wallace, 1990; Saito et al., 1993). The fact that regenerating axons in vivo can form presynaptic specializations on synaptic basal lamina, where agrin is concentrated, suggests its possible involvement (Sanes et al., 1978; McMahan, 1990). There is evidence that neurotrophins may also play a role in presynaptic development, as suggested by their effect on enhancing the transmitter release (Lohof et al., 1993). The skeletal muscle can synthesize several neurotrophins, including brain-derived neurotrophic factor and neurotrophin-3 (Henderson et al., 1993). In addition to their roles in motoneuron survival, it is conceivable that they may also be involved in the regulation of synaptogenesis. Whether the presynaptic induction is mediated by a specific molecule or by a multiplicity of molecules remains to be determined. The bead-neurite culture model used in this study should be useful in assaying the role of these molecules in synaptogenesis.

\section{References}

Anderson MJ, Fambrough DM (1983) Aggregates of acetylcholine receptors are associated with plaques of a basal lamina heparan sulfate proteoglycan on the surface of skeletal muscle fibers. J Cell Biol 97: 1396-1411.

Anderson MJ, Klier FG, Tanguay KE (1984) Acetylcholine receptor aggregation parallels the deposition of a basal lamina proteoglycan. J Cell Biol 99:1769-1784.

Baker LP, Peng HB (1993) Tyrosine phosphorylation and acetylcholine receptor cluster formation in cultured Xenopus muscle cells. J Cell Biol 120:185-195.

Betsholtz C, Johnsson A, Heldin C-H, Westermark B (1986) Efficient reversion of simian sarcoma virus-transformation and inhibition of growth factor-induced mitogenesis by suramin. Proc Natl Acad Sci USA 83:6440-6444

Betz WJ, Bewick GS (1992) Optical analysis of synaptic vesicle recycling at the frog neuromuscular junction. Science 255:200-202. 
Betz WJ, Henkel AW (1994) Okadaic acid disrupts clusters of synaptic vesicles in frog motor nerve terminals. J Cell Biol 124:843-854.

Burry RW (1980) Formation of apparent presynaptic elements in response to poly-basic compounds. Brain Res 184:85-98.

Burry RW, Ho RH, Matthew WD (1986) Presynaptic elements formed on polylysine-coated beads contain synaptic vesicle antigens. J Neurocytol 15:409-419.

Cohen MW, Jones OT, Angelides KJ (1991) Distribution of $\mathrm{Ca}^{2+}$ channels on frog motor nerve terminals revealed by fluorescent omegaconotoxin. J Neurosci 11:1032-1039.

Corfas G, Falls DL, Fischbach GD (1993) ARIA, a protein that stimulates acetylcholine receptor synthesis, also induces tyrosine phosphorylation of a $185-\mathrm{kDa}$ muscle transmembrane protein. Proc Natl Acad Sci USA 90:1624-1628.

Dai Z, Peng HB (1993) Elevation in presynaptic $\mathrm{Ca}^{2+}$ level accompanying initial nerve-Inuscle contact in tissue culture. Neuron 10: $827-837$.

Dai Z, Peng HB (1994) Mobility of synaptic vesicles during presynaptic development in cultured neurons studied with FM1-43. Soc Neurosci Abstr 20:632.

Dan Y, Poo M-M (1994) Retrograde interactions during formation and elimination of neuromuscular synapses. Curr Opin Neurobiol 4:95100.

Dauchel MC, Courty J, Mereau A, Barritault D (1989) Modulation of mitogenic activity and cellular binding of basic fibroblast growth factor by basic proteins. J Cell Biochem 39:411-420.

DeLapeyrière $\mathrm{O}$, Ollendorff $\mathrm{V}$, Planche $\mathrm{J}$, Ott MO, Pizette $\mathrm{S}$, Coulier $\mathrm{F}$, Birnbaum D (1993) Expression of the Fgf-6 gene is restricted to developing skeletal muscle in the mouse embryo. Development 118 : $601-611$.

DiMario J, Buffinger N, Yamada S, Strohman RC (1989) Fibroblast growth factor in the extracellular matrix of dystrophic (mdx) mouse muscle. Science 244:688-690.

Edwards FA, Gibb AJ, Colquhoun D (1992) ATP receptor-mediated synaptic currents in the central nervous system. Nature 359:144-147.

Forscher P, Lin CH, Thompson C (1992) Novel form of growth cone motility involving site-directed actin filament assembly. Nature 357 : 515-518.

Fu W-M, Poo M (1991) ATP potentiates spontaneous transmitter release at developing neuromuscular synapses. Neuron 6:837-843.

Funte LR, Haydon PG (1993) Synaptic target contact enhances presynaptic calcium influx by activating cAMP-dependent protein kinase during synaptogenesis. Neuron 10:1069-1078.

Gonzalez A-M, Buscaglia M, Ong M, Baird A (1990) Distribution of basic fibroblast growth factor in the 18-day rat fetus: localization in the basement membrane of diverse tissues. J Cell Biol 110:753-765.

Hall ZW, Sanes JR (1993) Synaptic structure and development: the neuromuscular junction. Neuron [Suppl] 10:99-121.

Han J-K, Martin GR (1993) Embryonic expression of $F g f-6$ is restricted to the skeletal muscle lineage. Dev Biol 158:549-554.

Han H-Q, Nichols RA, Rubin MR, Bähler M, Greengard P (1991) Induction of formation of presynaptic terminals in neuroblastonla cells by synapsin IIb. Nature 349:697-700.

Henderson CE, Camu W, Mettling C, Gouin A, Poulsen K, Karihaloo M, Rullamas J, Evans 'I, McMahon SB, Armanini MP, Berkemeier L, Phillips HS, Rosenthal A (1993) Neurotrophins promote motor neuron survival and are present in embryonic limb bud. Nature 363: $266-270$.

Hirokawa N, Sobue K, Kanda K, Harada A, Yorifuji H (1989) The cytoskeletal architecture of the presynaptic terminal and molecular structure of synapsin I. J Cell Biol 108:111-126.

Hughes RA, Sendtner M, Goldfarb M, Lindholm D, Thoenen H (1993) Evidence that fibroblast growth factor 5 is a major muscle-derived survival factor for cultured spinal motoneurons. Neuron 10:369-377.

Johnson DE, Lee PL, Lu J, Williams LT (1990) Diverse forms of a receptor for acidic and basic fibroblast growth factors. Mol Cell Biol 10:4728-4736.

Klagsbrun M, Baird A (1991) A dual receptor system is required for basic fibroblast growth factor activity. Cell 67:229-231.

Kuo M-D, Huang SS, Huang IS (1990) Acidic fibroblast growth factor receptor purified from bovine liver is a novel protein tyrosine kinase. J Biol Chem 265:16455-16463.

Lee PL, Johnson DE, Cousens LSJ, Fried VA, Williams LT (1989) Purification and complementary DNA cloning of a receptor for basic fibroblast growth factor. Science 245:57-60.
Levitzki A (1992) Tyrphostins: tyrosine kinase blockers as novel antiproliferative agents and dissectors of signal transduction. FASEB J 6:3275-3282.

Li Y-S, Milner PG, Chauhan AK, Watson MA, Hoffman RM, Kodner CM, Milbrandt J, Deuel TF (1990) Cloning and expression of a developmentally regulated protein that induces mitogenic and neurite outgrowth activity. Science 250:1690-1694.

Lohof AM, Ip NY, Poo M (1993) Potentiation of developing neuromuscular synapses by the neurotrophins NT-3 and BDNF. Nature 363:350-353.

Lyall RM, Zilberstein A, Gazit A, Gilon C, Levitzki A, Schlessinger J (1989) Tyrphostins inhibit epidermal growth factor (EGF)-receptor tyrosine kinase activity in living cells and EGF-stimulated cell proliferation. J Biol Chem 264:14503-14509.

Matteoli M, Haimann C, Torri-Tarelli F, Polak JM, Ceccarelli B, De Camilli P (1988) Differential effect of $\alpha$-latrotoxin on exocytosis from small synaptic vesicles and from large dense-core vesicles containing calcitonin gene-related peptide at the frog neuromuscular junction. Proc Natl Acad Sci USA 85:7366-7370.

Matthew WD, Tsavaler L, Reichardt LF (1981) Identification of a synaptic vesicle-specific membrane protein with a wide distribution in neuronal and neurosecretory tissue. J Cell Biol 91:257-269.

McMahan UJ (1990) The agrin hypothesis. Cold Spring Harbor Symp 50:407-418.

Merenmies J, Rauvala H (1990) Molecular cloning of the $18-\mathrm{kDa}$ growth-associated protein of developing brain. J Biol Chem 265: $16721-16724$

Peng HB (1983) Cytoskeletal organization of the presynaptic nerve terminal and the acetylcholine receptor cluster in cell cultures. J Cell Biol 97:489-498.

Peng HB, Markey DR, Muhlach WL, Pollack ED (1987) Development of presynaptic specializations induced by basic polypeptide-coated latex beads in spinal cord cultures. Synapse 1:10-19.

Peng HB, Baker LP, Chen Q (1991a) Induction of synaptic development in cultured muscle cells by basic fibroblast growth factor. Neuron 6:237-246.

Peng HB, Baker LP, Chen Q (1991b) Tissue culture of Xenopus neurons and muscle cells as a model for studying synaptic induction. In: Methods in cell biology, Vol 36, Xenopus laevis: practical uses in cell and molecular biology (Kay BK, Peng HB, eds), pp 511-526. San Diego: Academic.

Puro DG, Mano T (1991) Modulation of calcium channels in human retinal glial cells by basic fibroblast growth factor: a possible role in retinal pathobiology. J Neurosci 11:1873-1880.

Qu Z, Moritz E, Huganir RL (1990) Regulation of tyrosine phosphorylation of the nicotinic acetylcholine receptor at the rat neuromuscular junction. Neuron 4:367-378.

Robitaille R, Adler EM, Charlton MP (1990) Strategic location of calcium channels at transmitter release sites of frog neuromuscular synapses. Neuron 5:773-779.

Ruoslahti E (1989) Proteoglycans in cell regulation. J Biol Chem 264: 13369-13372.

Ruoslahti E, Yamaguchi Y (1991) Proteoglycans as modulators of growth factor activities. Cell 64:867-869.

Saito M, Nguyen J, Kidokoro Y (1993) Inhibition of nerve- and agrininduced acetylcholine receptor clustering on Xenopus muscle cells in culture. Dev Brain Res 71:9-17.

Sanes JR, Marshall LM, McMahan UJ (1978) Reinnervation of muscle fiber basal lamina after removal of muscle fibers. J Cell Biol 78:176198.

Swenarchuk LE, Champaneria S, Anderson MJ (1990) Induction of a specialized muscle basal lamina at chimaeric synapses in culture. Development 110:51-61.

Wallace BG (1990) Inhibition of agrin-induced acetylcholine-receptor aggregation by heparin, heparan sulfate, and other polyanions. J Neurosci 10:3576-3582.

Wallace BG, Qu Z. Huganir RL (1991) Agrin induces phosphorylation of the nicotinic acetylcholine receptor. Neuron 6:869-878.

Xie ZP, Poo M-M (1986) Initial events in the formation of neuromuscular synapse: rapid induction of acetylcholine release from embryonic neuron. Proc Natl Acad Sci USA 83:7069-7073.

Yayon A, Klagsbrun M (1990) Autocrine transformation by chimeric signal peptide-basic fibroblast growth factor: reversal by suramin. Proc Natl Acad Sci USA 87:5346-5350.

Zoran MJ, Funte LR, Kater SB, Haydon PG (1993) Neuron-muscle contact changes presynaptic resting calcium set-point. Dev Biol 158 : 163-171. 